\title{
Isolation, Diversity, and Antimicrobial Activity of Fungal Endophytes from Rohdea chinensis (Baker) N.Tanaka (synonym Tupistra chinensis Baker) of Qinling Mountains, China
}

\author{
Chao An ${ }^{1,2}$, Saijian Ma ${ }^{1,2}$, Xinwei Shi ${ }^{2,3}$, Wenjiao Xue ${ }^{\text {Corresp., 1, } 2}$, Chen Liu ${ }^{1,2}$, Hao Ding ${ }^{1,2}$ \\ ${ }^{1}$ Shaanxi Institute of Microbiology, Xi' an, Shaanxi, China \\ 2 Engineering Center of QinLing Mountains Natural Products, Shaanxi Academy of Sciences, Xi' an, Shaanxi, China \\ ${ }^{3}$ Shaanxi Institute of Botany,Xi' an Botanical Garden, Xi' an, Shaanxi, China \\ Corresponding Author: Wenjiao Xue \\ Email address: x-wenjiao@163.com
}

Endophytic fungi have been emerged as fruitful resources for producing structurally fascinating and biologically active secondary metabolites. However, endophytic fungi from medicinal plants of Qinling Mountains--the most important natural climatic boundary between the subtropical and warm temperate zones of China with an astonishingly high level of biodiversity--have rarely been explored as potential sources of novel fungal species and active secondary metabolites. In this study, a total of 371 fungal colonies were successfully isolated from 510 tissue segments of the medicinal Tupistra chinensis Baker collected from Qinling Mountains, China. Roots of $T$. chinensis Baker are used as a folk medicine to ameliorate pharyngitis and treat rheumatic diseases. A total of 100 representative morphotype strains were identified according to ITS rDNA sequence analyses and were grouped into three phyla (Ascomycota, Basidiomycota, Mucoromycota), seven classes (Dothideomycetes, Sordariomycetes, Eurotiomycetes, Microbotryomycetes, Agaricomycetes, Leotiomycetes, Mortierellomycetes), and at least 35 genera. The genera of Collectotrichum (IF, 29.92\%), Fusarium (IF, 8.36\%), Aspergillus (IF, 8.09\%), and Dactylonectria (IF, 5.39\%) were most frequently isolated from the tissues of $T$. chinensis Baker. The Species Richness Index $(S, 65)$ and the Shannon-Wiener Index $\left(H^{\prime}, 3.7914\right)$ indicated that $T$. chinensis Baker harbored abundant fungal resources. Moreover, five isolates were potential new taxa because of low similarity of ITS sequences ranged from 95.09\% 96.61\%. Fifteen out of 100 endophytic fungal ethyl acetate extracts exhibited inhibitory activities against at least one pathogenic bacterium or fungus. Two important lead compounds produced by two stains (F8047 and F8075) with high antimicrobial activities were identified using high performance liquid chromatography (HPLC) and ultraperformance liquid chromatography-quadrupole-time of flight mass spectrometry 
(UPLC-QTOF MS) analyses. In addition, it was noteworthy that the strain F8001, which may be a potential new species, showed antimicrobial activity and should be investigated further. Overall, these results indicated that the endophytic fungi from $T$. chinensis Baker could be exploited as a novel source of bioactive compounds. 
1 Isolation, Diversity, and Antimicrobial Activity of Fungal Endophytes from Rohdea

2 chinensis (Baker) N.Tanaka (synonym Tupistra chinensis Baker) of Qinling Mountains,

\section{China}

4

5

6 Chao An ${ }^{1,2}$, Sai-jian Ma1,2, Xin-wei Shi²,3, Wen-jiao Xue ${ }^{1,2}$, Chen Liu'1,2, Hao Ding ${ }^{1,2}$

7

8

$9{ }^{1}$ Shaanxi Institute of Microbiology, Xi'an 710043, China

$10{ }^{2}$ Engineering Center of QinLing Mountains Natural Products, Shaanxi Academy of Sciences,

11 Xi'an 710043, China

$12{ }^{3}$ Xi' an Botanical Garden, Shaanxi Institute of Botany, Xi'an 710061, China

15 Corresponding Author:

16 Wen-jiao Xue ${ }^{1}$

17 Shaanxi Institute of Microbiology, No. 76 Xiying Rd, Xi'an, Shaanxi Province, 710043, P. R.

18 China

19 Email address: x-wenjiao@163.com 
20

21

22

23

24

\section{Abstract}

Endophytic fungi have been emerged as fruitful resources for producing structurally fascinating and biologically active secondary metabolites. However, endophytic fungi from medicinal plants of Qinling Mountains--the most important natural climatic boundary between the subtropical and warm temperate zones of China with an astonishingly high level of biodiversity--have rarely been explored as potential sources of novel fungal species and active secondary metabolites. In this study, a total of 371 fungal colonies were successfully isolated from 510 tissue segments of the medicinal Tupistra chinensis Baker collected from Qinling Mountains, China. Roots of $T$. chinensis Baker are used as a folk medicine to ameliorate pharyngitis and treat rheumatic diseases. A total of 100 representative morphotype strains were identified according to ITS rDNA sequence analyses and were grouped into three phyla (Ascomycota, Basidiomycota, Mucoromycota), seven classes (Dothideomycetes, Sordariomycetes, Eurotiomycetes, Microbotryomycetes, Agaricomycetes, Leotiomycetes, Mortierellomycetes), and at least 35 genera. The genera of Collectotrichum (IF, 29.92\%), Fusarium (IF, 8.36\%), Aspergillus (IF, 8.09\%), and Dactylonectria (IF, 5.39\%) were most frequently isolated from the tissues of $T$. chinensis Baker. The Species Richness Index $(\mathrm{S}, 65)$ and the Shannon-Wiener Index $\left(H^{\prime}\right.$, 3.7914) indicated that $T$. chinensis Baker harbored abundant fungal resources. Moreover, five isolates were potential new taxa because of low similarity of ITS sequences ranged from 95.09\% 96.61\%. Fifteen out of 100 endophytic fungal ethyl acetate extracts exhibited inhibitory activities against at least one pathogenic bacterium or fungus. Two important lead compounds produced by two stains (F8047 and F8075) with high antimicrobial activities were identified using high performance liquid chromatography (HPLC) and ultra-performance liquid chromatography-quadrupole-time of flight mass spectrometry (UPLC-QTOF MS) analyses. In addition, it was noteworthy that the strain F8001, which may be a potential new species, showed antimicrobial activity and should be investigated further. Overall, these results indicated 
45 that the endophytic fungi from $T$. chinensis Baker could be exploited as a novel source of 46 bioactive compounds. 


\section{Introduction}

48 Due to the increase in antibiotic resistance among pathogens, discovering novel antimicrobials 49 is of high importance (Payne et al., 2007). However, after many decades of exploration it is 50 increasingly difficult to discover novel bioactive metabolites from common environments (e.g., 51 soils) (Jiang et al., 2018; Zhang et al., 2018; Lopes et al., 2016). Thus, in recent years the 52 discovery of novel bioactive metabolites from extremophilic microorganisms inhabiting marine 53 environments, desert soils, hot springs, and mangrove forests have attracted great interest 54 (Rateb et al., 2011; Nicoletti \& Vinale, 2018; Sayed et al., 2019). In addition, endophytic fungi 55 that inhabit the interiors various plant tissues without causing disease (Petrini et al., 1991) have 56 been increasingly identified as a source of novel metabolites. Medicinal plants harbor a great 57 diversity of culturable endophytes (Tan et al., 2015; Tan et al., 2018; Gong et al., 2019), which have can produce structurally fascinating and biologically active secondary metabolites (Helaly et al., 2018; Kumari et al., 2018; Leylaie \& Zafari, 2018; Mousa et al., 2015).

The goal of this study was to isolate fungal endophytes from T. chinensis Baker of Qinling Mountains region and to screen these fungi for antimicrobial activities and identify compounds using high performance liquid chromatography (HPLC) and ultra-performance liquid chromatography-quadrupole-time of flight mass spectrometry (UPLC-QTOF MS) analyses. The Qinling Mountains $\left(32^{\circ} 30^{\prime}-34^{\circ} 45^{\prime} \mathrm{N}, 104^{\circ} 30^{\prime}-112^{\circ} 45^{\prime} \mathrm{E}\right)$, which is mainly located in the south of Shaanxi province in central China, is the most important natural climatic boundary between the subtropical and warm temperate zones of China, and supports an astonishingly high biodiversity (Ma et al., 2018; Yuan et al., 2017; Huang et al., 2016; Wang et al., 2018). T. chinensis Baker grows in the valleys at altitudes of 500-2400 m in Qinling Mountains region. The genus Tupistra (Liliaceae), which has 12 species in China, is an important biological resource used as a folk medicine (Xiang et al., 2016a). The dried rhizome of T. chinensis Baker is reputed to be used as

71 Chinese folk medicine to ameliorate pharyngitis and treat rheumatic diseases (Xiang et al., 72 2016a; Xiang et al., 2016b). Previously, it was reported that T. chinensis Baker produced the 
73 antifungal compounds against Pseudoperonospora cubensis and Phytophthora infestans (Zhu

74 et al., 2018). However, to date there is no report on the diversity and antimicrobial activity of

75 endophytic fungi isolated from T. chinensis Baker.

76

77 Materials \& Methods

78 Plant material

79 A total of twenty wild plants of $T$. chinensis Baker were collected from Yingpan town, Shaanxi

80 province of China $\left(33^{\circ} 49^{\prime} 22^{\prime \prime} \mathrm{N}, 109^{\circ} 6^{\prime} 11^{\prime \prime} \mathrm{E}\right.$, altitude, $\left.1180 \mathrm{~m}\right)$. The land we accessed was

81 publicly owned and undeveloped. These plants were carefully dug up, placed in sterile sampling

82 bag, labeled, immediately transported to the laboratory, and then placed them into a refrigerator

$83\left(4^{\circ} \mathrm{C}\right)$ as described previously (Tan et al., 2014). Endophyte isolation procedures were

84 performed within $48 \mathrm{~h}$ of collection.

85

86

Fungal isolation and cultivation

87 The plant tissues were processed with the method described by Qin et al. (2009). In brief, the samples were thoroughly washed in running water for $30 \mathrm{~min}$, followed by a ultrasonic cleaning (200 W, $10 \mathrm{~min}$ ), and then air-dried for $2 \mathrm{~h}$ at room temperature. After drying, the plant samples were surface-sterilized with the protocol described by Tan et al. (2012) with minor modifications. Air-dried plant samples were surface-sterilized using sequential washes in $70 \%$ ethanol for $1 \mathrm{~m}$, $2.5 \% \mathrm{NaClO}_{2}$ for $2 \mathrm{~m}, 70 \%$ ethanol for $1 \mathrm{~m}$. Following sterilization, leaves were rinsed three times in sterile distilled water. We divided the 20 plants into root and stem tissues, which were then excised into 510 segments of $1-2 \mathrm{~mm}$ length (root segments: $n=270$; stem segments: $n=$ 240). Segments were placed on a series of isolation media including potato dextrose agar (PDA), malt extract agar (MEA) and sabouraud agar (SDA) medium using $90 \mathrm{~mm}$ petri plates.

97 Each isolation medium was amended with amikacin sulfate $(100 \mathrm{U} / \mathrm{mL})$ to prevent the growth of bacteria. Seven tissue segments were placed on each Petri dish $(90 \mathrm{~mm})$, which were then 
99

100

101

102

103

104

105

106

107

108

109

110

111

112

113

114

115

116

117

118

119

120

121

122

123

124

sealed with parafilm and incubated at $28^{\circ} \mathrm{C}$ for one week. Emergent fungal colonies were isolated and purified in PDA medium for further identification and bioactive assays (see below).

Pure isolates growing on PDA medium were photographed and the agar piece plugs with pure isolates were stored at $-80^{\circ} \mathrm{C}$ in a $20 \%$ glycerol solution in engineering center of QinLing Mountains natural products, Shaanxi provincial institute of microbiology.

\section{Molecular identification and phylogenetic analyses}

To obtain fungal mycelia, each pure isolate was cultivated on plates containing PDA medium at $28^{\circ} \mathrm{C}$ for 7 days. Mycelia were removed from media using sterile pipette tips and then ground in liquid nitrogen for DNA extraction using the TaKaRa MiniBEST Bacteria Genomic DNA Extraction Kit (Dalian, China). Genomic DNA was then used as the template for PCR amplification of the nuclear ribosomal DNA internal transcribed spacer (ITS) using the universal primers ITS1 (5'-TCCGTAGGTGAACCTGCGG-3') and ITS4 (5'-TCCTCCGCTTATTGATATGC3') according to the description by White et al. (1990) with minor modifications. The final reaction volume was $50 \mu \mathrm{L}$, containing $5.0 \mu \mathrm{L}$ of $10 \times$ Taq buffers, $4.0 \mu \mathrm{L}$ of $200 \mathrm{mmol} / \mathrm{L}$ dNTPs, $2.0 \mu \mathrm{L}$ of each primer at $10 \mu \mathrm{M}, 0.5 \mu \mathrm{L}$ of Ex Taq enzyme (TaKaRa, Dalian), and 5.0 $\mu \mathrm{L}$ of genomic DNA. PCR amplification was performed using TProfessional Standard 96 Gradient (Biometra, Germany) using the following cycling parameters: $1 \mathrm{~min} 95^{\circ} \mathrm{C}$; followed by 35 cycles of $15 \mathrm{~s}$ at $95^{\circ} \mathrm{C}, 30 \mathrm{~s}$ at $55^{\circ} \mathrm{C}$, and $1 \mathrm{~m}$ at $72{ }^{\circ} \mathrm{C}$; and a final $10 \mathrm{~m}$ extension at $72{ }^{\circ} \mathrm{C}$. Five $\mu \mathrm{L}$ of each PCR product was analyzed electrophoretically in $1 \%(\mathrm{w} / \mathrm{v})$ agarose gels stained with GelRed (Shanghai Generay Biotech Co., Ltd, China). The PCR products were subsequently purified and sequenced by BGI Biotechnology (Shenzheng, China). The raw obtained sequences were aligned using MEGA 5.05, edited manually, and then BLAST (Basic Local Alignment Search Tool) was used to search for the best match in the National Center for Biotechnology Information (NCBI) GenBank database (http://www.ncbi.nlm.nih.gov/) to identify endophytic fungi. Sequences with similarity over $97 \%$ belonged to the same genus. The sequences 
125 obtained in this study were submitted to GenBank database with accession numbers from

126 MK367469 to MK367568. The evolutionary history was inferred as described by Wei et al. (2018)

127 and Felsenstein (1985). All sequences were aligned by MEGA 5.05 using alignment prepared

128 with Clustal W and all positions containing gaps and missing date were deleted. Finally, the

129 maximum likelihood phylogenetic trees were constructed for each of families using MEGA

130 software 5.05 (Stamatakis, 2006).

131

132 Crude extract preparation of fungal fermentation broth

133 Each isolate was cultured on PDA for 7 days, after which the plugs of each fungus were used to

134 inoculate liquid cultures containing $250 \mathrm{~mL}$ Erlenmeyer flask containing $50 \mathrm{~mL}$ potato dextrose

135 (PD) culture medium containing $200 \mathrm{~g} / \mathrm{L}$ potato extract and $20 \mathrm{~g} / \mathrm{L}$ dextrose. All isolates were

136 incubated on a rotary shaker at $28^{\circ} \mathrm{C}$ and $230 \mathrm{rpm}$ for 14 days. The fermentation broth was

137 collected by centrifugation at $8000 \mathrm{rpm}$ for $8 \mathrm{~min}$. Fifty $\mathrm{mL}$ of fermentation filtrate was extracted

138 with $50 \mathrm{~mL}$ ethyl acetate (three extractions total) and the organic phase was concentrated using

139 a rotary evaporator on $50^{\circ} \mathrm{C}$ water bath to remove organic solvent as described by Xing et al.

140 (2011) with minor modifications. The crude extracts were diluted with pure methanol to 10

$141 \mathrm{mg} / \mathrm{mL}$ and sterilized by filtration using an organic filter $(0.22 \mu \mathrm{m}$, Shanyu Co., Ltd, China).

142

143 Antimicrobial activity

144 Using the agar diffusion method described by Wang et al. (2019), we screened the ethyl acetate

145 crude extracts from fermentation filtrates of 100 fungal strains for antimicrobial activities against

146 seven pathogens, including Bacillus cereus, Escherichia coli, Bacillus subtilis, Staphylococcus

147 aureus, Pseudomonas aeruginosa, Xanthomonas oryzae pv. oryzae and Candida albicans. The

148 detailed operation procedure are as follows: $10 \mathrm{~mL}$ culture of the $C$. albicans grown 2 days in

149 Sabouraud liquid medium at $28^{\circ} \mathrm{C}$ was added to the $200 \mathrm{~mL}$ of the Sabouraud agar medium,

150 while $10 \mathrm{~mL}$ cultures of pathogenic bacteria grown $12 \mathrm{~h}$ in the Luria-Bertani (LB) liquid medium 
151 at $28^{\circ} \mathrm{C}$ was added to the $100 \mathrm{~mL}$ of the LB agar medium, mixed gently, and then poured slowly

152 on the petri dish $(90 \mathrm{~mm})$ used as the test plate. Six $\mathrm{mm}$ sterilized straws were used for

153 perforating the plate, and the agar blocks were removed with sterilized toothpick. The $100 \mu \mathrm{L}$

154 fermentation filtrate EtoAc extracts $(10 \mathrm{mg} / \mathrm{mL})$ were added to the hole of the test plate. The

155 plates were incubated at $37^{\circ} \mathrm{C}$ for $24 \mathrm{~h}$ for the pathogenic bacteria or at $28^{\circ} \mathrm{C}$ for $48 \mathrm{~h}$ for $\mathrm{C}$.

156 albicans. Ampicillin sodium $(1 \mathrm{mg} / \mathrm{mL})$ and Actidione $(1 \mathrm{mg} / \mathrm{mL})$ were used as a positive

157 antimicrobial controls and pure methanol was used as a negative control. Antimicrobial activities

158 were evaluated by measuring the diameter of the inhibition zones. All experiments were

159 replicated three times.

160

161

\section{Identification of antimicrobial compounds by HPLC and UPLC-QTOF MS analyses}

We identified antimicrobial compounds using HPLC and UPLC-QTOF MS with the procedure described by Tan et al. (2018) and Hu et al. (2016). In brief, ethyl acetate crude extracts were dissolved in $2 \mathrm{~mL}$ pure methanol and were filtered through $0.22-\mu \mathrm{m}$ syringe filters prior to UPLCQTOF MS analyses (WATERS I-Class VION IMS QTof). Chromatographic separation was performed with ACQUITY UPLC BEH C18 column $(1.7 \mu \mathrm{m}, 2.1 \times 100 \mathrm{~mm})$ with an injection and $0.1 \%$ formic acid in methanol (B) as follows: 0-5.0 min, 5-50\% B; 5.0-12.0 min, 50-100\% B; temperature of the column oven was set to $35^{\circ} \mathrm{C}$. The MS was operated in negative ion mode and was set to total ion chromatogram mode with the following mass conditions: capillary voltage $=1.0 \mathrm{kV}$, low collision energy $=6 \mathrm{~V}$, source temperature $=100^{\circ} \mathrm{C}$, desolvation

173 temperature $=500^{\circ} \mathrm{C}$, and desolvation gas flow $=800 \mathrm{~L} / \mathrm{h}$. Data acquistition and processing were 174 conducted using Masslynx version (Waters, Manchester, UK).

\section{Diversity analyses of the endophytic fungi}


177 The isolation rate (IR) was calculated using the formula: IR $(\%)=(N i / N t) \times 100, N i$ : the

178 number of the segments isolated the fungal species, Nt: the total number of segments incubated.

179 The isolation frequency (IF) represented the frequency of the occurrence of certain endophytic

180 fungi in total isolates based on the number of isolates $(N)$. The relative abundance (RA) was

181 calculated based on the number of all isolates number $(\mathrm{N})$. The diversity of fungal species from

$182 T$. chinensis Baker was evaluated using the Species Richness Index $(S)$ and Shanon-Weiner

183 Index $\left(H^{\prime}\right)$ with the procedure described by Fedor \& Spellerberg. (2013). Species Richness

184 Index $(S)$ was obtained by counting the number of endophytic fungal species in corresponding

185 plant tissues. The proportions of the endophytic fungi against each pathogen were calculated

186 according to the number of strains with inhibitory activity for each pathogen, a total of 100

187 endophytic fungi were participated in antimicrobial activities assessment in this study.

188

189

Results

190

Isolation, sequencing, and diversity of the endophytic fungi from $T$. chinensis

191

In this study, a total of 371 fungal colonies were successfully isolated from 510 tissue segments

192

of $T$. chinensis Baker with three different isolation media (Table 1). The greatest number of

193

endophytic fungi were isolated on the PDA medium (IR, 41.24\%), followed by SDA medium (IR,

194

$38.27 \%$ ) and MEA medium (IR, 20.49\%). In contrast, similar IR values were obtained for roots

195

and shoots. The 371 isolates initially were assigned to 100 representative morphotypes

196

according to their culture characteristics on PDA. ITS rDNA sequences subsequently were

197

generated for a representative of each morphotype (Supplementary information files (1)). Based

198

on the sequence similarity threshold (SSA, 97\% 100\%) 95 isolates were categorized at the

199

genus level, while the remaining five isolates remained unidentified at the genus level.

200 Phylogenetic analyses using maximum likelihood (Supplementary information files (2)) identified

20135 fungal genera representing three phyla (Ascomycota, Basidiomycota, Mucoromycota), seven

202 classes (Dothideomycetes, Sordariomycetes, Eurotiomycetes, Microbotryomycetes, 
203 Agaricomycetes, Leotiomycetes, Mortierellomycetes), 15 orders, 24 families, 35 genera and 65

204 taxon (Fig. 1 \& Table 1). The Species Richness Index (S) and Shannon-Wiener Index $\left(H^{\prime}\right)$, 205 which are two important parameters for diversity analysis, were 65 and 3.7914 for $T$. chinensis 206 Baker, respectively.

207 Similar to previous studies using culture-based methods (Hamzah et al., 2018; Yao et al., 208 2016; Li et al., 2016), the majority of fungi isolated from T. chinensis Baker were identified as 209 Ascomycota (RA, 96.77\%), which represented 31 genera. In addition, three genera belonged to 210 Basidiomycota (RA, 2.42\%), and only one genus belonged to Mucoromycota (RA, 0.81\%).

211 Dothideomycetes, Sordariomycetes and Eurotiomycetes have been reported as the three 212 dominant classes in previous studies of endophytic fungi (Li et al., 2016; Tan et al., 2018; Yao et 213 al., 2016). In our present study, Sordariomycetes (RA, 70.89\%) was most abundant class, 214 followed by the Eurotiomycetes (RA, 13.48\%) and Dothideomycetes (RA, 11.86\%), which was 215 agreement with the previous studies (Tan et al., 2018) (Fig. 1A). Fig. 1B presented the RA of 216 endophytic fungi at the order level and Glomerellales (RA, 31.01\%) was the most abundant 217 community in this study. Glomerellaceae (RA, 29.92\%), Nectriaceae (RA, 15.90\%), 218 Aspergillaceae (RA, 12.94\%) were three most abundant families in this study as shown in Fig. $2191 \mathrm{C}$ and 16 families including Coniochaetaceae, Mortierellaceae, Phaeosphaeriaceae, 220 Trichocomaceae, Trichosphaeriaceae, Periconiaceae, Leptosphaeriaceae, Pleosporaceae, 221 Aspergillaceae, Rhytismataceae, Valsaceae, Stachybotryaceae, Lasiosphaeriaceae, 222 Trichosphaeriaceae, Sporocadaceae, Entolomataceae, Sporidiobolaceae have only one 223 species of the endophytic fungi from $T$. chinensis Baker. In addition, the distribution of 224 endophytic fungi varied in different tissues as shown in Fig. 1(D-I).

225 In previous studies, Colletotrichum, Fusarium, Aspergillus were the dominant genera of 226 endophytes in different host plants (Tan et al., 2018; Gong et al., 2019; Salazar-Cerezo et al., 227 2018) and similar result was obtained in this study (Colletotrichum (IF, 29.92\%), Fusarium (IF, 
228 8.36\%), Aspergillus (IF, 8.09\%)). In addition, fungi representing the genera Biscogniauxia, 229 Leptosphaeria, Leptostroma, Annulohypoxylon, Stachybotrys, Didymella, Peniophora, 230 Dactylonectria, Nectria, Peniophora, Rhodotorula, Setophaeosphaeria, Clitopilus were obtained 231 in this study. Endophytes in these genera have been reported much less frequently in previous 232 studies (Sritharan et al., 2019; Gong et al., 2019; Li et al., 2018).

233

234 Antimicrobial activity screening of the ethyl acetate extracts from endophytic fungal 235 culture filtrates

236 As shown in Table 2, 15 out of 100 endophytic fungal ethyl acetate extracts (15\%) showed 237 inhibitory activity against at least one pathogenic bacterium or fungus (Supplementary 238 information files (3)). The other 85 extracts did not show inhibitory activities. The proportions of 239 inhibitory activity against different pathogens were 7\% (B. cereum), 6\% (B. subtilis), 6\% (S. 240 aureus), 2\% (P. aeruginosa), 4\% (C. albicans), 1\% (E. coli), and 4\% (X. oryzae pv. oryzae), 241 respectively. The relatively low proportion of activity against the Gram-negative bacterium such 242 as E. coli (1\%) and $P$. earuginosa (2\%) were observed, which was in accordance with previous 243 studies (Deshmukh et al., 2014).

244 The isolated strains with antimicrobial activity belonged to genera of Leptospora,

245 Chaetomium, Leptostroma, Annulohypoxylon, Biscogniauxia, Penicillium, Nigrospora, Nemania, 246 Cylindrocarpon, Clitopilus, Fusarium, Trichoderma, Aspergillus, respectively (Table 2). Among 247 of these strains, Nigrospora sp. F8047 and Clitopilus sp. F8075 exhibited high antimicrobial 248 activity. The inhibitory zone diameter against C. albicans of ethyl acetate extracts from F8047 249 was $19.5 \pm 0.3 \mathrm{~mm}$ and the inhibitory zone diameter against $S$. aureus of ethyl acetate extracts 250 from F8075 reached $43.6 \pm 0.8 \mathrm{~mm}$.

252 Identification of antimicrobial compounds from the strains F8047 and F8075 
253 We used HPLC and UPLC-QTOF MS to analyze the antimicrobial compounds in the ethyl 254 acetate extracts of the strains Nigrospora sp. F8047 and Clitopilus sp. F8075. The result of 255 HPLC analysis showed that one of compounds in the ethyl acetate extracts from this strain had 256 a same retention time with the standard griseofulvin (Fig. 2A \& Fig. 2B). The MS spectra also 257 showed the peak of $\mathrm{MH}^{+}$at $\mathrm{m} / \mathrm{z} 352.0789$ (Fig. 2C) for the corresponding compound from this 258 strain was similar with that for griseofulvin standard (m/z 352.0788) (Fig. 2D). The results 259 suggested that griseofulvin was an antifungal activity compound in ethyl acetate extracts from 260 the strain F8047. In previous studies, species of Nigrospora have been widely reported to 261 produce griseofulvin (Rathod et al. 2014).

262 The antibacterial compound of ethyl acetate extracts from strain Clitopilus sp. F8075, which 263 showed high inhibitory activity against $S$. aureus with the inhibitory zone diameter $43.6 \pm 0.8 \mathrm{~mm}$, 264 were identified by UPLC-QTOF MS analyses (Fig. 3A). The results showed that one of 265 compounds in the extracts from this strain had a peak of $\mathrm{MH}^{+}$at $\mathrm{m} / \mathrm{z} 378.2482$ (Fig. 3B), which 266 was the similar molecular weight with the pleurotropin $(\mathrm{m} / \mathrm{z} 378.5)$. We speculated that the pleurotropin, which had been reported to be produced by Clitopilus spp. (Bailey et al., 2016; De Mattos-Shipley et al., 2017), was an antibacterial compound in ethyl acetate extracts of the strain F8075. Later experiments confirmed the speculation and pleuromutilin was purified from the fermentation broth of F8075 guided by LC-MS and antimicrobial activity (data not shown).

\section{Discussion}

273 The Qinling Mountains are rich in medicinal plant resources, many of which have been used as

274 traditional Chinese medicines by the local people. In recent years, increasing attention has

275 focused on biodiversity and pharmacological properties of medicinal plants of the Qinling

276 Mountains; however, as far as we know, few studies have attempted to evaluate the diversity of 277 endophytes associated with these valuable plants. (Li et al., 2016). In this study, we investigated 
278 the diversity of the culturable endophytic fungi from T. chinensis Baker, which is one of most 279 popular medicinal plants in Qinling Mountains.

280 Our results indicated that the plants harbored endophytic fungi with high diversity, 281 comparable to recent studies on other medicine plants ( Li et al., 2016; Yao et al., 2016; Zhou et 282 al., 2017; Tan et al., 2018; Chen et al., 2019b). In addition, we isolated five fungal strains that 283 may represent new species, as sequences in the NCBI GenBank database had low sequence 284 similarity (i.e., 95.09\% 96.61\%) (Vu et al., 2019). Our results indicate that T. chinensis Baker 285 could be exploited as a novel source of endophytic fungi with antimicrobial activities, and we 286 believe that other medicinal plants in Qinling Mountains also have the potential to be valuable 287 resources for endophytic fungi.

288 Although the roots of $T$. chinensis Baker have been used in the traditional formulations, we 289 isolated endophytes from both the stem and the root. It is notable that 36 species were obtained 290 from the roots and 35 species from the stem of the T. chinensis Baker. Only six species 291 (Aspergillus flavipes, Aspergillus sp., Penicillium oxalicum, Merimbla ingelheimensis, 292 Colletotrichum sp. and Fusarium oxysporum) were cultured from both root and stem tissues. 293 The result implicated that different tissues of $T$. chinensis Baker harbored different endophytic 294 fungal species, although species richness and Shannon-Wiener diversity index were similar for 295 different tissues of the plants.

296 Endophytic fungi have been emerged as fruitful resources for producing structurally 297 fascinating and biologically active secondary metabolites (Sunil et al., 2015; Sunil et al., 2018). 298 In our research, ethyl acetate extracts of 15 endophytic fungi (15\% of total screened) showed 299 inhibitory activity against pathogenic microorganisms. These 15 isolates represent fungal 300 genera previously reported to produce antimicrobial compounds (Ouyang et al.,2018; Kamdem 301 et al., 2018; Yu et al., 2018; Deshmukh et al., 2014). However, new bioactive compounds are 302 constantly being discovered from plant endophytes (Rateb et al., 2011; Sayed et al., 2019;

303 Chen et al., 2019a). Thus, the fungi with antimicrobial activity obtained in this study still have the 
304 potential to produce new structures natural products. In addition, it is noteworthy that the strain 305 F8001, which may be a potential new species, showed antifungal activity and should be further 306 researched.

307

308 Conclusions

309 In this study, the diversity and antimicrobial activities of the endophytic fungi from $T$. chinensis

310 Baker were investigated for the first time. Our results illustrate that $T$. chinensis Baker harbors

311 abundant fungal endophytes representing a diversity of taxonomic affiliations, including

312 potentially new species. We found that 15 out of 100 endophytic fungal ethyl acetate extracts

313 exhibited inhibitory activities against at least one of the pathogenic microorganisms. Specifically,

314 the strains F8047 and F8075 with high antimicrobial activities produced two important types of 315 antibiotics compounds. In addition, it was noteworthy that the strain F8001, which may be a 316 potential new species, showed antifungal activity and should be investigated further. Overall, 317 these results indicated that the endophytic fungi from $T$. chinensis Baker could be exploited as a 318 novel source of bioactive compounds.

319

320 Funding

321 This project was funded by the National Natural Science Foundation of China (21576160), the 322 Science and Technology Research Project of Shaanxi Province Academy of Sciences (2018nk323 01, 2018k-09), the Shaanxi Science and Technology Project (2017NY-192; 2018NY-152;

$3242019 N Y-209)$. The funders had no role in study design, data collection and analysis, decision to 325 publish, or preparation of the manuscript.

327 Grant Disclosures

328 The following grant information was disclosed by the authors:

329 National Natural Science Foundation of China: 21576160. 
330 Science and Technology Research Project of Shaanxi Province Academy of Sciences: 2018nk33101.

332 Science and Technology Research Project of Shaanxi Province Academy of Sciences: 2018k33309.

334 Shaanxi Science and Technology Project: 2017NY-192.

335 Shaanxi Science and Technology Project: 2018NY-152.

336 Shaanxi Science and Technology Project: 2019NY-209. 
337

338

339

340

341

342

343

344

345

346

347

348

349

350

351

352

353

354

355

356

357

\section{References}

Bailey AM, Alberti F, Kilaru S, Collins CM, de Mattos-Shipley K, Hartley AJ, Hayes P, Griffin A, Lazarus CM, Cox RJ, Willis CL, O'Dwyer K, Spence DW, Foster GD. 2016. Identification and manipulation of the pleuromutilin gene cluster from Clitopilus passeckerianus for increased rapid antibiotic production. Scientific Reports 6:25202-25212 DOI 10.1038/srep25202.

Chen S, Li H, Chen Y, Li S, Xu J, Guo H, Liu Z, Zhu S, Liu H, Zhang W. 2019a. Three new diterpenes and two new sesquiterpenoids from the endophytic fungus Trichoderma koningiopsis A729.Bioorganic Chemistry 86:368-374 DOI 10.1016/j.bioorg.2019.02.005.

Chen X, Luo X, Fan M, Zeng W, Yang C, Wu J, Zhao C, Zhang Y, Zhao P. 2019b.

Endophytic fungi from the branches of Camellia taliensis (W. W. Smith) Melchior, a widely distributed wild tea plant. World Journal of Microbiology and Biotechnology 35 (7):113 DOI 10.1007/s11274-019-2686-x.

Cheng Z, Xu W, Liu L, Li S, Yuan W, Luo Z, Zhang J, Cheng Y, Li Q. 2018. Peniginsengins $\mathrm{B}^{-} \mathrm{E}$, new farnesylcyclohexenones from the deep sea-derived fungus Penicillium sp. YPGA11. Marine Drugs 16(10):358-368 DOI 10.3390/md16100358.

De Mattos-Shipley KMJ, Foster GD, Bailey AM. 2017. Insights into the classical geneticsof Clitopilus passeckerianus - the pleuromutilin producing mushroom. Frontiers in Microbiology 8:1056-1066 DOI 10.3389/fmicb.2017.01056.

Deshmukh SK, Verekar SA, Bhave SV. 2014. Endophytic fungi: a reservoir of antibacterials. Frontiers in Microbiology 5: 715 DOI 10.3389/fmicb.2014.00715. 
358 Fedor PJ, Spellerberg IF. 2013. Shannon-Wiener Index. Reference Module in Earth Systems and Environmental Sciences. DOI 10.1016/b978-0-12-409548-9.00602-3.

360

Felsenstein J. 1985. Confidence limits on phylogenies: an approach using the bootstrap. Evolution 39(4): 783-791 DOI 10.1111/j.1558-5646.1985.tb00420.x.

Gong A, Zhou T, Xiao C, Jiang W, Zhou Y, Zhang J, Liang Q, Yang C, Zheng W, Zhang C. 2019. Association between dipsacus saponinVI level and diversity of endophytic fungi in roots of Dipsacus asperoides. World Journal of Microbiology and Biotechnology 35(3):42-56 DOI 10.1007/s11274-019-2616-y.

Hamzah TNT, Lee SY, Hidayat A, Terhem R, Faridah-Hanum I, Mohamed R. 2018. Diversity and characterization of endophytic fungi isolated from the tropical mangrove species, Rhizophora mucronata, and identification of potential antagonists against the soil-borne fungus, Fusarium solani. Frontiers in Microbiology 9:1707-1724 DOI 10.3389/fmicb.2018.01707.

Helaly SE, Thongbai B, Stadler M. 2018. Diversity of biologically active secondary metabolites from endophytic and saprotrophic fungi of the ascomycete order Xylariales. Natural Product Reports 35(9):992-1014 DOI 10.1039/c8np00010g.

Hu YJ, Deng LQ, Chen JW, Zhou SY, Liu S, Fu YF, Yang CX, Liao ZH, Chen M. 2016. An analytical pipeline to compare and characterise the anthocyanin antioxidant activities of purple sweet potato cultivars. Food Chemistry 194(1):46-54 DOI 10.1016/j.foodchem.2015.07.133. 
378 Huang M, Duan R, Wang S, Wang Z, Fan W. 2016. Species presence frequency and diversity

379 in different patch types along an altitudinal gradient: Larix chinensis Beissn in Qinling

$380 \quad$ Mountains (China). Peerj 4 e1803 DOI 10.7717/peerj.1803.

381 Jiang ZK, Tuo L, Huang DL, Osterman IA, Tyurin AP, Liu SW, Lukyanov DA, Sergiev PV,

382 Dontsova OA, Korshun VA, Li FN, Sun CH. 2018. Diversity, novelty, and antimicrobial

383 activity of endophytic actinobacteria from mangrove plants in beilun estuary national nature

384 reserve of Guangxi, China. Frontiers in Microbiology 9:868-879 DOI

385

10.3389/fmicb.2018.00868.

Kamdem RST, Pascal W, Rehberg N, van Geelen L, Höfert SP, Knedel TO, Janiak C,

Metabolites from the endophytic fungus Cylindrocarpon sp. isolated from tropical plant

Sapium ellipticum. Fitoterapia 128:175-179 DOI 10.1016/j.fitote.2018.05.020.

390

391

Kumari M, Taritla S, Sharma A, Jayabaskaran C. 2018. Antiproliferative and antioxidative bioactive compounds in extracts of marine-derived endophytic fungus Talaromyces purpureogenus. Frontiers in Microbiology 9:1777-1791 DOI 10.3389/fmicb.2018.01777.

Leylaie S, Zafari D. 2018. Antiproliferative and antimicrobial activities of secondary metabolites and phylogenetic study of endophytic Trichoderma species from Vinca plants. Frontiers in Microbiology 9:1484-1500 DOI 10.3389/fmicb.2018.01484.

Li C, Hu Z, Liu Q, Wu X, Cao S. 2018. Two new tricycloalternarenes from Hawaiian endophytic fungus Didymella sp. FT433. Tetrahedron Letters 59(36):3381-3383 DOI 10.1016/j.tetlet.2018.07.061. 
399 Li P, Wu Z, Liu T, Wang Y. 2016. Biodiversity, phylogeny, and antifungal functions of

400 endophytic fungi associated with Zanthoxylum bungeanum. International Journal of

$401 \quad$ Molecular Sciences 17(9):1541-1565 DOI 10.3390/ijms17091541.

402 Lopes A, Rodrigues MJ, Pereira C, Oliveira M, Barreira L, João V, Trampetti F, Custódio L.

403 2016. Natural products from extreme marine environments: searching for potential industrial

404 uses within extremophile plants. Industrial Crops and Products 94:299-307 DOI

$405 \quad$ 10.1016/j.indcrop.2016.08.040.

406 Ma T, Hu Y, Russo IM, Nie Y, Yang T, Xiong L, Ma S, Meng T, Han H, Zhang X, Bruford

407

MW, Wei F. 2018. Walking in a heterogeneous landscape: dispersal, gene flow and

408

conservation implications for the giant panda in the Qinling Mountains. Evolutionary

409

Applications 11(10):1859-1872 DOI 10.1111/eva.12686.

410

Ma YM, Ma CC, Li T, Wang J. 2015. A new furan derivative from an endophytic Aspergillus

flavus of Cephalotaxus fortunei. Narural Product Research 30(1):79-84 DOI

412

10.1080/14786419.2015.1038262.

Mousa WK, Schwan A, Davidson J, Strange P, Liu H, Zhou T, Auzanneau FI, Raizada MN.

2015. An endophytic fungus isolated from finger millet (Eleusine coracana) produces antifungal natural products. Frontiers in Microbiology 6:1157-1173 DOI

10.3389/fmicb.2015.01157.

417 Nicoletti R, Vinale F. 2018. Bioactive compounds from marine-derived Aspergillus, Penicillium,

418 Talaromyces and Trichoderma Species. Marine Drugs 16(11):408-411 DOI

$419 \quad 10.3390 / \mathrm{md} 16110408$. 
420

421

422

423

424

425

426

427

428

429

430

431

432

Ouyang J, Mao Z, Guo H, Xie Y, Cui Z, Sun J, Wu H, Wen X, Wang J, Shan T. 2018.

Mollicellins O-R, Four new depsidones isolated from the endophytic fungus Chaetomium sp.

Eef-10. Molecules 23(12):3218-3229 DOI 10.3390/molecules23123218.

Payne DJ, Gwynn MN, Holmes DJ, Pompliano DL. 2007. Drugs for bad bugs: confronting the challenges of antibacterial discovery. Nature Reviews Drug Discovery 6(1):29-40 DOI 10.1038/nrd2201.

Petrini O. 1991. Fungal endophytes of tree leaves. In: Andrews JH,Hirano SS (eds) Microbial ecology of leaves. Springer, New York, pp 179-197.

Qin S, Li J, Chen HH, Zhao GZ, Zhu WY, Jiang CL, Xu LH, Li WJ. 2009. Isolation, diversity, and antimicrobial activity of rare actinobacteria from medicinal plants of tropical rain forests in Xishuangbanna, China. Applied Environmental Microbiology 75(19): 6176-6186 DOI 10.1128/AEM.01034-09.

Rateb ME, Houssen WE, Arnold M, Abdelrahman MH, Deng H, Harrison WTA, Okoro CK, Asenjo JA, Andrews BA, Ferguson G, Bull AT, Goodfellow M, Ebel R, Jaspars M. 2011. Chaxamycins A-D, bioactive ansamycins from a hyper-arid desert Streptomyces sp. Journal of Natural Products 74:1491-1499 DOI 10.1021/np200320u.

Rathod DP, Dar MA, Gade AK, Rai MK. 2014. Griseofulvin producing endophytic Nigrospora oryzae from indian emblica officinalis gaertn: a new report. Austin Journal of Biotechnology \& Bioengineering 3:1-5. 
439

440

441

442

443

444

445

446

447

448

449

450

451

452

453

454

455

Salazar-Cerezo S, Martinez-Montiel N, Cruz-Lopez MDC, Martinez-Contreras RD. 2018.

Fungal diversity and community composition of culturable fungi in Stanhopea trigrina cast gibberellin producers. Frontiers in Microbiology 9:612-646 DOI 10.3389/fmicb.2018.00612.

Sayed AM, Hassan MHA, Alhadrami HA, Hassan HM, Goodfellow M, Rateb ME. 2019.

Extreme environments: microbiology leading to specialized metabolites. Journal of Applied Microbiology 198 DOI: 10.1111/jam.14386.

Sritharan T, Savitri Kumar N, Jayasinghe L, Araya H, Fujimoto Y.2019. Isocoumarins and dihydroisocoumarins from the endophytic fungus Biscogniauxia capnodes isolated from the fruits of Averrhoa carambola. Natural Product Communications 14(5): DOI $110.1177 / 1934578 \times 19851969$.

Stamatakis A. 2006. RAxML-VI-HPC: maximum likelihood based phylogenetic analyses with thousands of taxa and mixed models. Bioinformatics 22:2688-2690 DOI 10.1093/bioinfor matics/btl446.

Sunil KD, Shilpa AV, Sarita VB. 2015. Endophytic fungi: a reservoir of antibacterials. Frontiers in microbiology 5: 715-758 DOI 10.3389/fmicb.2014.00715.

Sunil KD, Manish KG, Ved P, Sanjai S. 2018. Endophytic fungi: a source of potential antifungal compounds. Journal of Fungi 4(3): 77-119 DOI 10.3390/jof4030077.

Tan XM, Chen XM, Wang C, Ji XH, Cui JL, Chen J, Guo SX, Zhao LF. 2012. Isolation and identification of endophytic fungi in roots of nine Holcoglossum plants (Orchidaceae) collected from Yunnan, Guangxi, and Hainan provinces of china. Current Microbiology 64(2):140-147 DOI 10.1007/s00284-011-0045-8. 
460 Tan XM, Wang CL, Chen XM, Zhou YQ, Wang YQ, Luo AX, Liu ZH, Guo SX. 2014. In vitro

461

462

463

464

465

466

467

468

469

470

471

472

473

474

475

476

477

478

479 seed germination and seedling growth of an endangered epiphytic orchid, Dendrobium

officinale, endemic to China using mycorrhizal fungi (Tulasnella sp.). Scientia Horticulturae

22: 62-68 DOI 10.1016/j.scienta.2013.10.031.

Tan XM, Zhou YQ, Zhou XL, Xia XH, Wei Y, He LL, Tang HZ, Yu LY. 2018. Diversity and bioactive potential of culturable fungal endophytes of Dysosma versipellis; a rare medicinal plant endemic to china. Scientific Reports 8(1):5929-5938 DOI 10.1038/s41598-018-24313-2.

Vu D, Groenewald M, De Vries M, Gehrmann T, Stielow B, Eberhardt U, , Al-Hatmi A, Groenewald JZ, Cardinali G, Houbraken J, Boekhout T, Crous PW, Robert V, Verkley GJM. 2019. Large-scale generation and analysis of filamentous fungal DNA barcodes boosts coverage for kingdom fungi and reveals thresholds for fungal species and higher taxon delimitation. Studies in Mycology 92:135-154 DOI 10.1016/j.simyco.2018.05.001.

Wang HH, Chu HL, Dou Q, Xie QZ, Tang M, Sung CK, Wang CY. 2018. Phosphorus and nitrogen drive the seasonal dynamics of bacterial communities in Pinus forest fhizospheric soil of the Qinling Mountains. Frontiers in Microbiology 9:1930 DOI

10.3389/fmicb.2018.01930.

Wang SS, Liu JM, Sun J, Sun YF, Liu JN, Jia N, Fan B, Dai XF. 2019. Diversity of cultureindependent bacteria and antimicrobial activity of culturable endophytic bacteria isolated from different Dendrobium stems. Scientific Reports 9(1):10389 DOI 10.1038/s41598-01946863-9. 
480

481

482

483

484

485

486

487

488

489

490

491

492

493

494

495

496

497

498

Wei W, Zhou Y, Chen F, Yan X, Lai Y, Wei C, Chen X, Xu J, Wang X. 2018. Isolation,

diversity, and antimicrobial and immunomodulatory activities of endophytic actinobacteria from Tea cultivars Zijuan and Yunkang-10 (Camellia sinensis var. assamica). Frontiers in Microbiology 9:1304-1315 DOI 10.3389/fmicb.2018.01304.

White TJ, Bruns T, Lee S, Taylor J. 1990. Amplification and direct sequencing of fungal ribosomal RNA genes for phylogenetics. In: PCR protocols: A guide to methods and applications. (Innis MA, Gelfand DH, Sninsky JJ, White TJ (eds) Academic press, New Yorks. p 315-322).

Xia X, Li Q, Shao C, Zhang J, Liu X, Lin Y, Liu C, She Z. 2011. Two new derivatives of griseofulvin from the mangrove endophytic fungus Nigrospora sp. (strain No. 1403) from Kandelia candel (L.) Druce. Planta Medica 77(15):1735-1738 DOI 10.1055/s-0030-1271040.

Xiang L, Wang Y, Yi X, Feng J, He X. 2016a. Furospirostanol and spirostanol saponins from the rhizome of Tupistra chinensis and their cytotoxic and anti-inflammatory activities. Tetrahedron 72(1):1-8 DOI 10.1016/j.tet.2015.11.012.

Xiang L, Wang Y, Yi X, Zheng G, He X. 2016b. Bioactive spirostanol saponins from the rhizome of Tupistra chinensis. Steroids (108):39-46 DOI 10.1016/j.steroids.2016.02.012.

Xing YM, Chen J, Cui JL, Chen XM, Guo SX. 2011. Antimicrobial activity and biodiversity of endophytic fungi in Dendrobium devonianum and Dendrobium thyrsiflorum from vietman. Current Microbiology 62(4):1218-1224 DOI 10.1007/s00284-010-9848-2. 
499 Yao YQ, Lan F, Qiao YM, Wei JG, Huang RS, Li LB. 2016. Endophytic fungi harbored in the

500 root of Sophora tonkinensis Gapnep: diversity and biocontrol potential against

501 phytopathogens. Microbiologyopen 6(3):1-17 DOI 10.1002/mbo3.437.

502 Yu HB, Jiao H, Zhu YP, Zhang JP, Lu XL, Liu XY. 2018. Bioactive metabolites from the Arctic

503 fungus Nectria sp. B-13. Journal of Asian Natural Products Research 21(10):1-9 DOI

$504 \quad 10.1080 / 10286020.2018 .1482880$.

505 Yuan J, Zheng X, Cheng F, Zhu X, Hou L, Li J, Zhang S. 2017. Fungal community structure

506 of fallen pine and oak wood at different stages of ecomposition in the Qinling Mountains,

507 China. Scientific Reports 7(1):13866 DOI 10.1038/s41598-017-14425-6.

508 Zhang X, Li SJ, Li JJ, Liang ZZ, Zhao CQ. 2018. Novel natural products from extremophilic

509 fungi. Marine Drugs 16(6):194 DOI 10. 3390/md16060194.

510 Zhou YK, Shen XY, Hou CL. 2017. Diversity and antimicrobial activity of culturable fungi from

511 fishscale bamboo (Phyllostachys heteroclada) in China. World Journal of Microbiology and

512 Biotechnology 33(6):104-111 DOI 10.1007/s11274-017-2267-9.

513 Zhu F, Yuan C, Gang F, Yang C, Wu W, Zhang J. 2018. Bioassay-guided isolation of

514 antifungal compounds from Disporopsis aspersa (HUA) ENGL. ex DIELS against

515 Pseudoperonospora cubensis and Phytophthora infestans. Chemistry \& biodiversity

$516 \quad$ 15(7):1-9 DOI 10.1002/cbdv.201800090. 


\section{Figure Legends}

\section{8}

519 Figure 1 Relative abundance (RA, \%) of endophytic fungi at the level of class $(A, D, G)$. order 520 (B, E, H), family (C, F, I).

521

522 Figure 2 Representative base peak ion chromatograms of strain F8047 ethyl acetate extracts

523 (A) and standard griseofulvin samples (B) from UPLC-QTOF MS analyses performed in

524 negative ion mode (C) standard griseofulvin (D) the arrow indicates the molecular ion of 525 griseofulvin at $\mathrm{m} / \mathrm{z} 352.0788$.

526

527 Figure 3 Representative base peak ion chromatograms of strain F8075 ethyl acetate extracts

528 (A) and the arrow indicates the molecular ion of pleuromutilin at $\mathrm{m} / \mathrm{z} 378.2482$. 


\section{Table Legends}

531

532 Table 1 Isolation frequency (IF) of each endophytic fungal species from $T$. chinensis Baker.

533

534 Table 2 Antimicrobial activities of culturable endophytic fungi from $T$. chinensis Baker. 


\section{Figure 1}

Figure 1 Relative abundance (RA, \%) of endophytic fungi at the level of class (A, D, G). $\operatorname{order}(B, E, H)$, family $(C, F, I)$

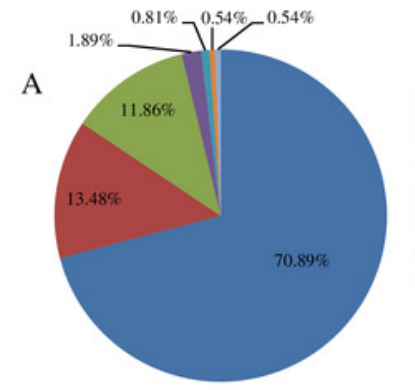

B
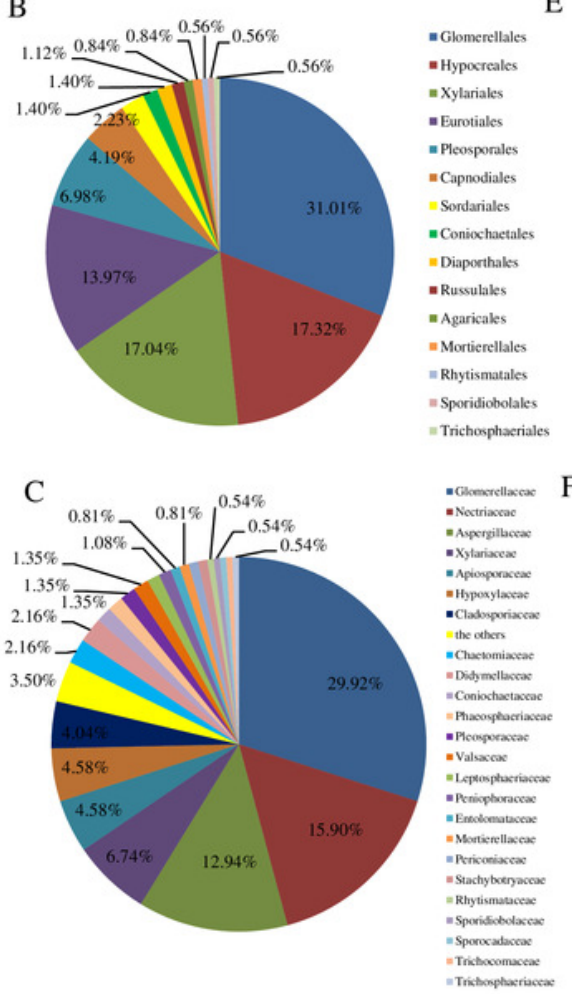

Total
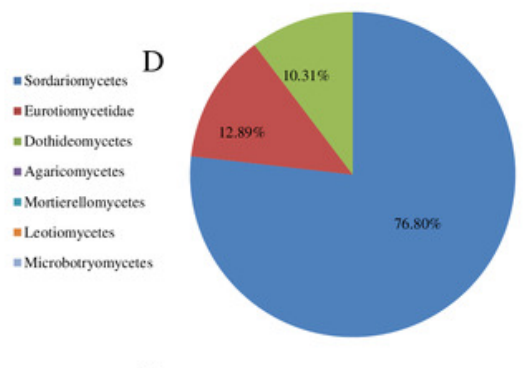

E
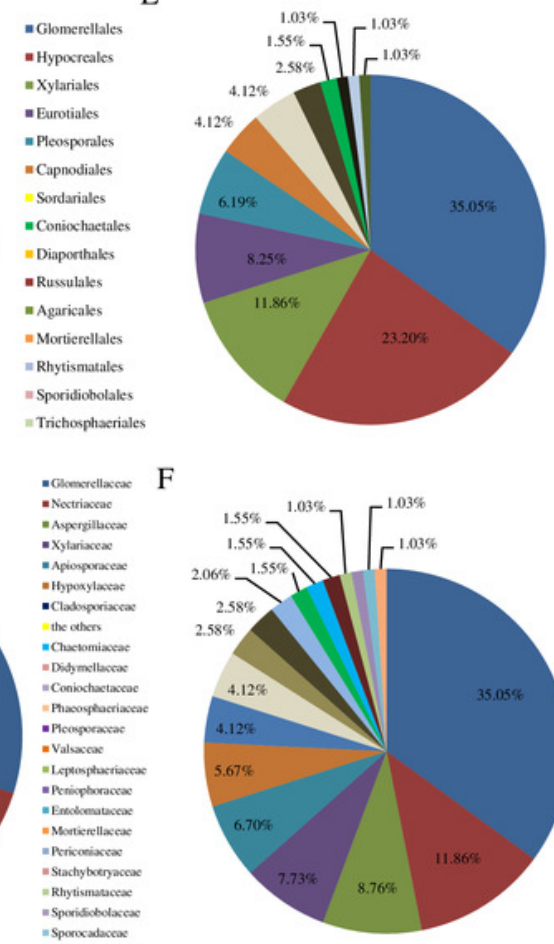

Root

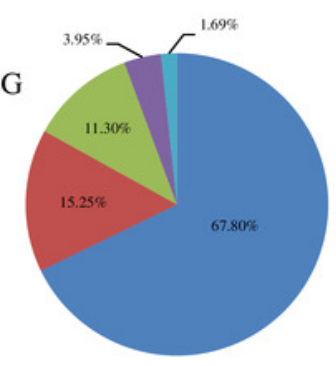

- Sordariomycetes

= Sordariomycetes

- Eurotiomycetidac

" Dothideomycetes

- Agaricomycetes

= Morticrellomycetes

$\mathrm{H}$
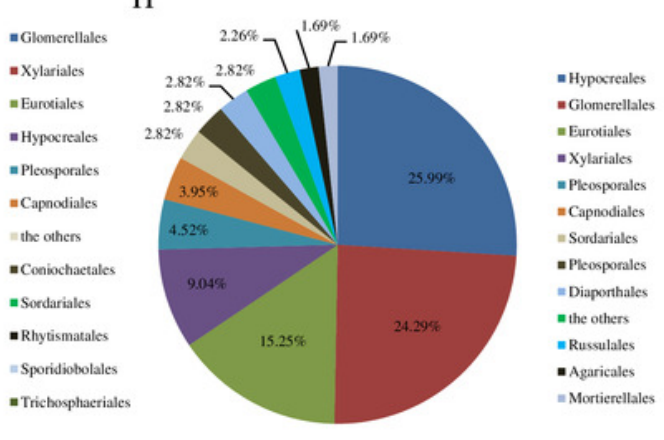

-Glomerellaceac I

- Aspergillaceac

- Apiosporaceac

-Xylariaceac

-Nectriaceac

- Hypoxylaceac

-Cladosporiac

"the others

=Coniochaetaceac

- Phacosphacriaceac

"Leptosphaeriaces

-Chactomiaces.

- Periconiaceac

- Stachybotryaceac

" Rhytismataceac

- Sporocadaceae

"Trichosphasiaceac

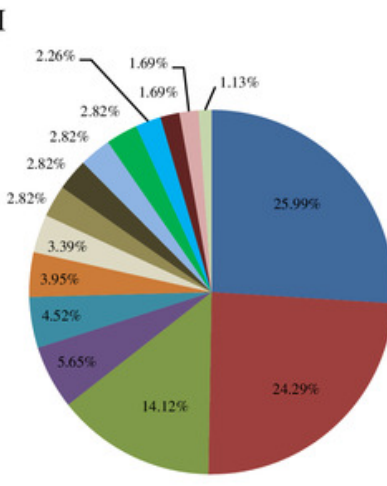

- Nectriacase

- Glomerellaceae

=Aspergillaceac

-Xylariaceac

-Didymellacese

=Cladosporiaceas

Hypoxylaceac

=Chatomiacese

- Plcosporaceac

"Valsacese

wthe others

- Peniophoraceac

-Emolomataceac

= Mortierellaceae
=Trichocomaceae

Stem 
Figure 2

Figure 2 Representative base peak ion chromatograms of strain F8047 ethyl acetate extracts (A) and standard griseofulvin samples (B) from UPLC-QTOF MS analyses performed in negative ion mode (C) standard griseofulvin (D) the arrow indicates the molecular 

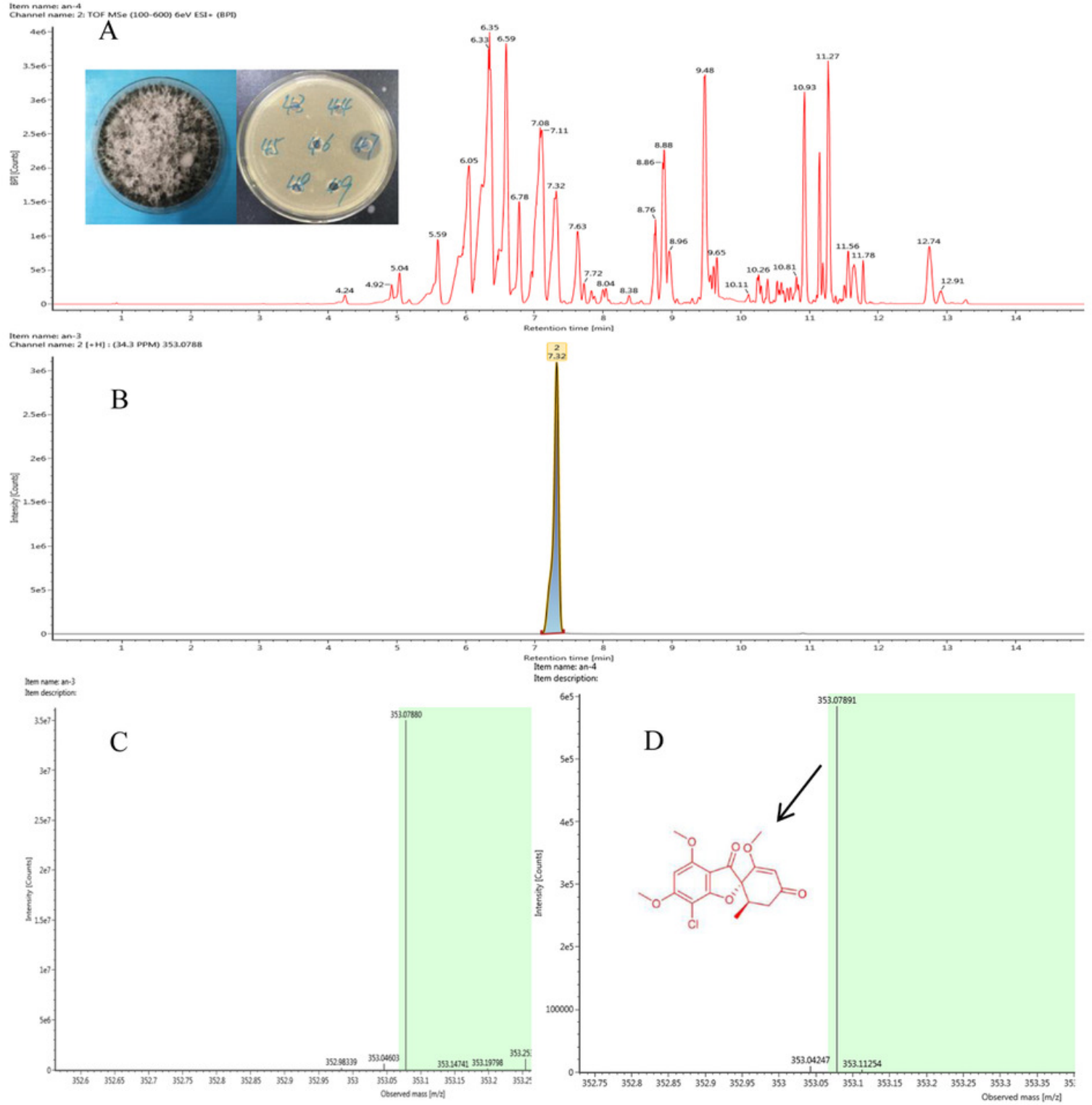
Figure 3

Figure 3 Representative base peak ion chromatograms of strain F8075 ethyl acetate extracts $(A)$ and the arrow indicates the molecular ion of pleuromutilin at $\mathrm{m} / \mathrm{z} 378.2482$ 9 


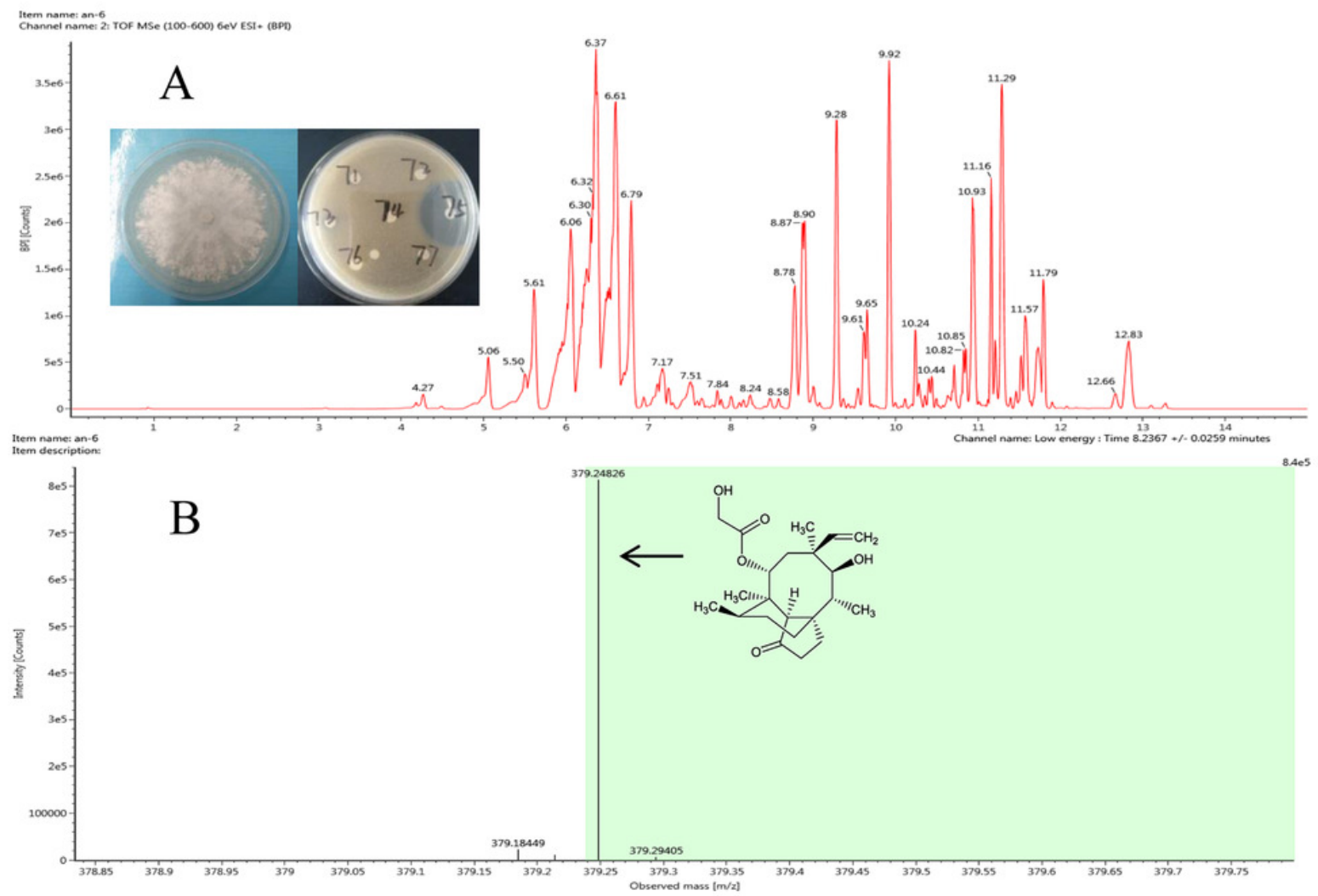




\section{Table 1 (on next page)}

Table 1 Isolation frequency (IF) of each endophytic fungal species from $T$. chinensis Baker 


\begin{tabular}{|c|c|c|c|c|c|c|c|c|c|c|c|c|c|c|c|c|c|c|}
\hline \multirow{3}{*}{ Closest species } & \multicolumn{8}{|c|}{ Root } & \multicolumn{8}{|c|}{ Leaf } & \multirow{2}{*}{\multicolumn{2}{|c|}{ Total }} \\
\hline & \multicolumn{2}{|c|}{ PDA } & \multicolumn{2}{|c|}{ SDA } & \multicolumn{2}{|c|}{ MEA } & \multicolumn{2}{|c|}{ Subtotal } & \multicolumn{2}{|c|}{ PDA } & \multicolumn{2}{|c|}{ SDA } & \multicolumn{2}{|c|}{ MEA } & \multicolumn{2}{|c|}{ Subtotal } & & \\
\hline & $N$ & $I F$ & $N$ & $I F$ & $N$ & $I F$ & $N$ & $I F$ & $N$ & $I F$ & $N$ & $I F$ & $N$ & $I F$ & $N$ & $I F$ & $N$ & $I F$ \\
\hline Cladosporium cladosporioides & - & - & - & - & - & - & - & - & 4 & 5.13 & 3 & 4.55 & - & - & 7 & 3.95 & 7 & 1.89 \\
\hline Cladosporium cucumerinum & - & - & 2 & 2.63 & 2 & 4.65 & 4 & 2.06 & - & - & - & - & - & - & - & - & 4 & 1.08 \\
\hline Cladosporium sp & 3 & 4.00 & - & - & 1 & 2.33 & 4 & 2.06 & - & - & - & - & - & - & - & - & 4 & 1.08 \\
\hline Leptospora rubella & - & - & 3 & 3.95 & - & - & 3 & 1.55 & - & - & - & - & - & - & - & - & 3 & 0.81 \\
\hline Didymella pinodella & - & - & - & - & - & - & - & - & 3 & 3.85 & - & - & - & - & 3 & 1.69 & 3 & 0.81 \\
\hline Phoma bellidis & - & - & - & - & - & - & - & - & - & - & 2 & 3.03 & - & - & 2 & 1.13 & 2 & 0.54 \\
\hline Phoma sp & - & - & - & - & - & - & - & - & 2 & 2.56 & - & - & - & - & 2 & 1.13 & 2 & 0.54 \\
\hline Periconia byssoides & 3 & 4.00 & - & - & - & - & 3 & 1.55 & - & - & - & - & - & - & - & - & 3 & 0.81 \\
\hline Leptosphaeria sp & 3 & 4.00 & - & - & 1 & 2.33 & 4 & 2.06 & - & - & - & - & - & - & - & - & 4 & 1.08 \\
\hline Setophoma terrestris & - & - & - & - & - & - & - & - & - & - & 2 & 3.03 & - & - & 2 & 1.13 & 2 & 0.54 \\
\hline Setophaeosphaeria citricola & 3 & 4.00 & 2 & 2.63 & - & - & 5 & 2.58 & - & - & - & - & - & - & - & - & 5 & 1.35 \\
\hline Alternaria alternata & - & - & - & - & - & - & - & - & 3 & 3.85 & 2 & 3.03 & - & - & 5 & 2.82 & 5 & 1.35 \\
\hline Pleosporales sp & - & - & 2 & 2.63 & - & - & 2 & 1.03 & - & - & - & - & - & - & - & - & 2 & 0.54 \\
\hline Aspergillus flavipes & - & - & 2 & 2.63 & 1 & 2.33 & 3 & 1.55 & 3 & 3.85 & 2 & 3.03 & - & - & 5 & 2.82 & 8 & 2.16 \\
\hline Aspergillus flavus & - & - & - & - & - & - & - & - & - & - & - & - & 2 & 6.06 & 2 & 1.13 & 2 & 0.54 \\
\hline Aspergillus hiratsukae & 2 & 2.67 & - & - & - & - & 2 & 1.03 & - & - & - & - & - & - & - & - & 2 & 0.54 \\
\hline Aspergillus pseudoglaucus & - & - & - & - & - & - & - & - & - & - & 2 & 3.03 & 3 & 9.09 & 5 & 2.82 & 5 & 1.35 \\
\hline Aspergillus sp & 2 & 2.67 & 3 & 3.95 & - & - & 5 & 2.58 & - & - & 2 & 3.03 & 2 & 6.06 & 4 & 2.26 & 9 & 2.43 \\
\hline Aspergillus sydowii & 2 & 2.67 & 2 & 2.63 & - & - & 4 & 2.06 & - & - & - & - & - & - & - & - & 4 & 1.08 \\
\hline Penicillium chrysogenum & - & - & - & - & - & - & - & - & 3 & 3.85 & - & - & 1 & 3.03 & 4 & 2.26 & 4 & 1.08 \\
\hline Penicillium citrinum & - & - & 2 & 2.63 & - & - & 2 & 1.03 & - & - & - & - & - & - & - & - & 2 & 0.54 \\
\hline Penicillium oxalicum & 2 & 2.67 & - & - & - & - & 2 & 1.03 & 2 & 2.56 & - & - & - & - & 2 & 1.13 & 4 & 1.08 \\
\hline Penicillium sp & 2 & 2.67 & - & - & - & - & 2 & 1.03 & - & - & - & - & - & - & - & - & 2 & 0.54 \\
\hline Talaromyces funiculosus & - & - & - & - & - & - & - & - & - & - & - & - & 2 & 6.06 & 2 & 1.13 & 2 & 0.54 \\
\hline
\end{tabular}




\begin{tabular}{|c|c|c|c|c|c|c|c|c|c|c|c|c|c|c|c|c|c|c|}
\hline Merimbla ingelheimensis & 3 & 4.00 & - & - & - & - & 3 & 1.55 & 3 & 3.85 & - & - & - & - & 3 & 1.69 & 6 & 1.62 \\
\hline Leptostroma $\mathrm{sp}$ & 2 & 2.67 & - & - & - & - & 2 & 1.03 & - & - & - & - & - & - & - & - & 2 & 0.54 \\
\hline Phomopsis lactucae & - & - & - & - & - & - & - & - & 3 & 3.85 & - & - & 2 & 6.06 & 5 & 2.82 & 5 & 1.35 \\
\hline Colletotrichum acutatum & 4 & 5.33 & 2 & 2.63 & 2 & 4.65 & 8 & 4.12 & - & - & - & - & - & - & - & - & 8 & 2.16 \\
\hline Colletotrichum godetiae & - & - & - & - & - & - & - & - & 5 & 6.41 & 4 & 6.06 & 1 & 3.03 & 10 & 5.65 & 10 & 2.70 \\
\hline Colletotrichum liriopes & - & - & - & - & - & - & - & - & 14 & 17.95 & 8 & 12.12 & 2 & 6.06 & 24 & 13.56 & 24 & 6.47 \\
\hline Colletotrichum sp & 9 & 12.00 & 6 & 7.89 & 3 & 6.98 & 18 & 9.28 & - & - & 3 & 4.55 & 2 & 6.06 & 5 & 2.82 & 23 & 6.20 \\
\hline Colletotrichum truncatum & 4 & 5.33 & 17 & 22.37 & 21 & 48.84 & 42 & 21.65 & - & - & - & - & - & - & - & - & 42 & 11.32 \\
\hline Annulohypoxylon annulatum & 4 & 5.33 & - & - & - & - & 4 & 2.06 & - & - & - & - & - & - & - & - & 4 & 1.08 \\
\hline Mortierella alpina & - & - & - & - & - & - & - & - & - & - & 3 & 4.55 & - & - & 3 & 1.69 & 3 & 0.81 \\
\hline Hypoxylon begae & 2 & 2.67 & - & - & - & - & 2 & 1.03 & - & - & - & - & - & - & - & - & 2 & 0.54 \\
\hline Hypoxylon fragiforme & 3 & 4.00 & - & - & - & - & 3 & 1.55 & - & - & - & - & - & - & - & - & 3 & 0.81 \\
\hline Hypoxylon $\mathrm{sp}$ & - & - & 2 & 2.63 & - & - & 2 & 1.03 & - & - & - & - & - & - & - & - & 2 & 0.54 \\
\hline Trichoderma citrinoviride & - & - & - & - & - & - & - & - & 3 & 3.85 & - & - & - & - & 3 & 1.69 & 3 & 0.81 \\
\hline Trichoderma $\mathrm{sp}$ & - & - & - & - & - & - & - & - & - & - & 3 & 4.55 & - & - & 3 & 1.69 & 3 & 0.81 \\
\hline Cylindrocarpon olidum & - & - & - & - & - & - & - & - & 3 & 3.85 & - & - & - & - & 3 & 1.69 & 3 & 0.81 \\
\hline Cylindrocarpon sp & 2 & 2.67 & - & - & - & - & 2 & 1.03 & - & - & - & - & - & - & - & - & 2 & 0.54 \\
\hline Dothideomycetes $s p$ & - & - & - & - & - & - & - & - & 3 & 3.85 & 3 & 4.55 & - & - & 6 & 3.39 & 6 & 1.62 \\
\hline Dactylonectria macrodidyma & - & - & - & - & - & - & - & - & 7 & 8.97 & 10 & 15.15 & 3 & 9.09 & 20 & 11.30 & 20 & 5.39 \\
\hline Fusarium oxysporum & 3 & 4.00 & - & - & - & - & 3 & 1.55 & 2 & 2.56 & 3 & 4.55 & 5 & 15.15 & 10 & 5.65 & 13 & 3.50 \\
\hline Fusarium proliferatum & - & - & - & - & - & - & - & - & 3 & 3.85 & - & - & - & - & 3 & 1.69 & 3 & 0.81 \\
\hline Fusarium sp & 5 & 6.67 & 3 & 3.95 & - & - & 8 & 4.12 & - & - & - & - & - & - & - & - & 8 & 2.16 \\
\hline Fusarium solani & - & - & - & - & - & - & - & - & 3 & 3.85 & 2 & 3.03 & 2 & 6.06 & 7 & 3.95 & 7 & 1.89 \\
\hline Nectria haematococca & - & - & - & - & - & - & - & - & 3 & 3.85 & - & - & - & - & 3 & 1.69 & 3 & 0.81 \\
\hline Stachybotrys echinata & - & - & 3 & 3.95 & - & - & 3 & 1.55 & - & - & - & - & - & - & - & - & 3 & 0.81 \\
\hline Chaetomium murorum & - & - & 3 & 3.95 & - & - & 3 & 1.55 & - & - & - & - & - & - & - & - & 3 & 0.81 \\
\hline Chaetomium nigricolor & - & - & - & - & - & - & - & - & - & - & - & - & 2 & 6.06 & 2 & 1.13 & 2 & 0.54 \\
\hline Chaetomium sp & - & - & - & - & - & - & - & - & - & - & 3 & 4.55 & - & - & 3 & 1.69 & 3 & 0.81 \\
\hline Coniochaeta sp & 3 & 4.00 & 2 & 2.63 & - & - & 5 & 2.58 & - & - & - & - & - & - & - & - & 5 & 1.35 \\
\hline
\end{tabular}




\begin{tabular}{|c|c|c|c|c|c|c|c|c|c|c|c|c|c|c|c|c|c|c|}
\hline Nigrospora oryzae & - & - & 4 & 5.26 & 3 & 6.98 & 7 & 3.61 & - & - & - & - & - & - & - & - & 7 & 1.89 \\
\hline Arthrinium camelliae-sinensis & - & - & - & - & 7 & 16.28 & 7 & 3.61 & - & - & - & - & - & - & - & - & 7 & 1.89 \\
\hline Arthrinium arundinis & - & - & 2 & 2.63 & - & - & 2 & 1.03 & - & - & - & - & - & - & - & - & 2 & 0.54 \\
\hline Arthrinium yunnanum & 3 & 4.00 & 5 & 6.58 & - & - & 8 & 4.12 & - & - & - & - & - & - & - & - & 8 & 2.16 \\
\hline Pestalotiopsis vismiae & - & - & 2 & 2.63 & - & - & 2 & 1.03 & - & - & - & - & - & - & - & - & 2 & 0.54 \\
\hline Biscogniauxia sp & 3 & 4.00 & - & - & - & - & 3 & 1.55 & - & - & - & - & - & - & - & - & 3 & 0.81 \\
\hline Nemania serpens & - & - & - & - & - & - & - & - & 3 & 3.85 & - & - & - & - & 3 & 1.69 & 3 & 0.81 \\
\hline Nemania sp & 3 & 4.00 & 7 & 9.21 & 2 & 4.65 & 12 & 6.19 & - & - & - & - & - & - & - & - & 12 & 3.23 \\
\hline Xylaria sp. & - & - & - & - & - & - & - & - & - & - & 5 & 7.58 & 2 & 6.06 & 7 & 3.95 & 7 & 1.89 \\
\hline Clitopilus sp. & - & - & - & - & - & - & - & - & 3 & 3.85 & - & - & - & - & 3 & 1.69 & 3 & 0.81 \\
\hline Peniophora cinerea & - & - & - & - & - & - & - & - & - & - & 2 & 3.03 & 2 & 6.06 & 4 & 2.26 & 4 & 1.08 \\
\hline Rhodotorula mucilaginosa & - & - & - & - & - & - & - & - & - & - & 2 & 3.03 & - & - & 2 & 1.13 & 2 & 0.54 \\
\hline Total & 75 & 100 & 76 & 100 & 43 & 100 & 194 & 100 & 78 & 100 & 66 & 100 & 33 & 100 & 177 & 100 & 371 & 100 \\
\hline Tissue numbers & & 90 & & 90 & & 90 & & 70 & & 80 & & 80 & & 80 & & & & \\
\hline$I F(\%)$ & & 3.33 & & 4.44 & & 7.78 & & 85 & & 97.5 & & 82.5 & & 1.25 & & & & \\
\hline Species richness (S) & \multicolumn{8}{|c|}{36} & \multicolumn{8}{|c|}{35} & \multicolumn{2}{|c|}{65} \\
\hline Shaanon-Wiener index $\left(H^{\prime}\right)$ & \multicolumn{8}{|c|}{3.1402} & \multicolumn{8}{|c|}{3.2661} & \multicolumn{2}{|c|}{3.7914} \\
\hline
\end{tabular}


Table 2 (on next page)

Table 2 Antimicrobial activities of culturable endophytic fungi from T. chinensis Baker 


\begin{tabular}{|c|c|c|c|c|c|c|c|c|}
\hline \multirow{2}{*}{$\begin{array}{l}\text { Isolates } \\
\text { No }\end{array}$} & \multirow{2}{*}{ Taxa (Accession number) } & \multicolumn{7}{|c|}{ Inhibition zone in diameter on Petri plate $(\mathrm{mm})$} \\
\hline & & B. cereus & E.coli & B. subtilis & S. aureus & P. aeruginosa & X. oryzae & C. albicans \\
\hline F8001 & Leptospora sp.(MK367469) & $19.3 \pm 0.2$ & - & - & $16.2 \pm 0.4$ & $11.5 \pm 0.3$ & - & - \\
\hline F8002 & Chaetomium sp.(MK367470) & - & - & - & $11.1 \pm 0.2$ & $10.2 \pm 0.3$ & - & - \\
\hline F8003 & Leptostroma sp.(MK367471) & - & - & - & $14.2 \pm 0.2$ & - & - & $17.2 \pm 0.4$ \\
\hline F8032 & Annulohypoxylon sp.(MK367499) & - & - & $15.4 \pm 0.3$ & - & - & - & - \\
\hline F8036 & Biscogniauxia sp.(MK367503) & $12.3 \pm 0.2$ & - & $14.3 \pm 0.4$ & - & - & - & - \\
\hline F8038 & Penicillium sp.(MK367505) & $15.7 \pm 0.3$ & - & $16.3 \pm 0.1$ & - & - & $15.3 \pm 0.4$ & - \\
\hline F8047 & Nigrospora sp.(MK367514) & - & - & - & - & - & - & $19.5 \pm 0.3$ \\
\hline F8049 & Nemania sp.(MK367516) & - & - & - & - & - & - & $11.3 \pm 0.2$ \\
\hline F8073 & Cylindrocarpon sp.(MK367537) & $12.3 \pm 0.2$ & - & $12.5 \pm 0.3$ & $12.6 \pm 0.3$ & - & $10.3 \pm 0.4$ & - \\
\hline F8075 & Clitopilus sp.(MK367539) & $14.6 \pm 0.3$ & - & $17.4 \pm 0.5$ & $43.6 \pm 0.8$ & - & $25.7 \pm 0.4$ & - \\
\hline F8076 & Nectria sp.( MK367540) & - & - & $12.3 \pm 0.2$ & $9.5 \pm 0.3$ & - & - & - \\
\hline F8080 & Chaetomium sp.(MK367544) & - & - & - & - & - & $12.4 \pm 0.3$ & - \\
\hline F8081 & Fusarium sp.(MK367545) & $17.5 \pm 0.5$ & & - & - & - & - & - \\
\hline F8086 & Trichoderma sp.(MK367549) & - & - & - & - & - & - & $20.6 \pm 0.8$ \\
\hline F8106 & Aspergillus sp.(MK367568) & $16.5 \pm 0.3$ & $16.8 \pm 0.5$ & - & - & - & - & - \\
\hline Total & 15 & 7 & 1 & 6 & 6 & 2 & 4 & 4 \\
\hline
\end{tabular}

